\section{Too late not to proliferate?}

\author{
David Fishlock examines the background to the \\ burgeoning international trade in nuclear technology
}

$\mathrm{D}^{\mathrm{R}}$ R Glenn Seaborg, the chemist who with E. M. McMillan first isolated plutonium, delivered a paper on "the plutonium economy of the future" in Santa $\mathrm{Fe}$ in 1970. It was an important paper; Seaborg, as chairman of the US Atomic Energy Commission, was forecasting that by 1990 one-quarter of the energy used by the USA could come from plutonium. By then, he said, the nation would have accumulated a plutonium stockpile from its light water reactors worth (at 1970 prices) about $\$ 6,000$ million-twice as much as the US investor-owned utilities had spent on fuel in 1969.

The paper attracted little attention. The campaign against nuclear energy in the US, although well under way, was almost wholly engaged in attacking the intrinsic safety of nuclear reactors. Proliferation of nuclear materials, although a subject of deep concern to a great many governments, was not a public issue, much less a target of anti-nuclear campaigners. Neither were nuclear weapons or nuclear materials then seen as serious targets for international terrorists.

By the mid-1970s, however, the antinuclear campaigners badly needed a new target. Although they had succeeding in slowing the pace of licencing and construction of reactors, they had failed completely to make out a case against them as a potential hazard. Not a single nuclear plant had been shut down because it was emitting, or was considered liable to emit, dangerous amounts of radiation.

Plutonium, and plans to refine and recycle it, and to use it to fuel more advanced types of reactor, offered a tempting new target. The very name of the element, its "fiendishly toxic properties" as one US physicist had once described them, and its immense potential as an explosive offered clear advantages in arousing public fears. Overnight the 'plutonium economy' became a catchphrase depicting a world unfit for human beings.

\section{Three events}

Three events contributed importantly to the widespread fears now aroused about the plutonium economy and its implications. The first, in May 1974, was the explosion by India of a plutonium device it euphemistically referred to as a "peaceful nuclear explosive". 'This was a profound shock

David Fishlock is Science Editor of the Financial Times, London. for those nations which for nearly 20 years had been striving for international controls on the use of nuclear technologies. In public India had declared repeatedly that it would never make a nuclear weapon. So, in spite of the fact that India had been opposed from the outset to any idea of international control and safeguards through the UN's International Atomic Energy Agency (IAEA), such nations as the US and Canada had provided India with nuclear technology and know-how, sometimes on very generous terms. Under the Colombo Aid programme Canada provided an NRX research reactor free from international safeguards. The Indians used this reactor to transmute natural uranium into plutonium.

The second event occurred about a year later, in the summer of 1975 , when after some months of publicity the West German Government signed a contract with Brazil to provide that country with virtually a ready-made nuclear industry, including the technology to separate plutonium and to enrich uranium. It was the biggest nuclear export contract any country had ever won. But the US Government had already turned down Brazil's requests for enrichment and reprocessing, not least because Brazil refused to sign the 1969 Non-Proliferation Treaty (NPT).

The furore over the GermanBrazilian contract also highlighted a number of other nuclear contracts under negotiation, notably contracts under which France planned to provide Pakistan and South Korea with reprocessing plants. Together with the Indian explosions, these negotiations prompted the US Government to bring together for the first time the seven leading nuclear supplier nations at a secret meeting in London to try to find more effective controls for the transfer of 'sensitive nuclear technologies'. These were then defined as the technologies of reprocessing and enrichment, both of which could be adapted to yield fissile materials, and the production of heavy water.

The third event of importance in establishing the plutonium economy as a public issue was the publication in September 1976 of the Sixth Report of the Royal Commission on Environmental Pollution, under the chairmanship of Sir Brian Flowers. In spite of the fact that Flowers had never once raised the matter as a part-time mem- ber of the UK Atomic Linergy Authority, this report expressed deep concern with the idea of any plutonium falling into the hands of terrorists. If the stability of our society continued to deteriorate, it suggested, proliferation of the sources and movements of plutonium could begin to pose a serious hazard.

Meanwhile the US Government had been abruptly awakened to the fact that it was fast losing control of technologies it had sought to control-for example, through its patronage of the IAEA and its domination of the enrichment and reactor markets-since the end of the Second World War. It searched desperately for fresh safeguards against proliferation. Dr Henry Kissinger, as Secretary of State, enthusiastically endorsed an IAEA idea for regional fuel cycle centres operating under international management and safeguards to serve such areas as Latin America and the Middle East with 'sensitive technologies'. A major study by the IAEA soon disclosed that while the regional concept was politically impractical--it was difficult to conceive of a project or a site that would serve Brazil, Argentina and Chile, for instance, or Egypt, Israel and Iran-the multinational reprocessing centre was a serious proposition. Where the centre was located was of small importance since transport costs varied little with distance. But economies of scale made the economic advantages of large plants attractive to any nation with purely commercial aims. The IAEA concluded that ideally a multinational reprocessing centre would be set up by five or seven nations, one or more of which would be able to provide the technology and organise the financing of plants expected to cost of the order of $\$ 1,000$ million. Such a centre would justify full-time surveillance by IAEA inspectors to ensure that no illegal diversion of plutonium took place.

\section{Interest waned}

Promising as the outcome of this study proved to be, the interest of the US Government had waned long before its formal presentation at the nuclear conference in Salzburg next month. At best it could be a medium-term solution, for such centres would need at least a decade to organise and bring into service. Even the technologically simpler problem of organising international plutonium storage might take a decade to bring about. The US was urgently searching for tighter controls against proliferation that could be implemented here and now.

Its response came finally in a statement on 7 April in which President Carter formally declared a moratorium on one of the sensitive technologies, 
reprocessing. In future the US would store the highly radioactive fuel from its light water reactors. The president took care at this time to stress that this was domestic US policy for controlling proliferation, and that it recognised that other nations with no indigenous uranium might not be so willing to forego the uranium and plutonium locked up in spent fuel.

During the month that followed two further aspects of US anti-proliferation policy emerged. One was that in order to try to persuade other nations to follow the US policy, America was going to expand her uranium enrichment capacity while still keeping this activity firmly under government control. The implication was that it was prepared to supply enriched uranium from its own reserves, enriched to the low level required in existing thermal reactors, and moreover would be prepared to store unreprocessed spent fuel for customers.

What also emerged, in a statement from Dr Joseph Nye, a senior State Department official concerned with anti-proliferation, was that the US would bring pressure to bear on forcign governments to follow its policy by refusing permission to reprocess, either at home or elsewhere, fuel which had previously been enriched in the US. In practice, this meant most of the enriched fuel extant in the West.

This ban could be implemented under the bilateral agreements covering enrichment of the original fuel. Where customers, said $\mathrm{Dr}$ Nye, were in special difficulties from lack of storage capacity, and plants might have to be shut down, the US Government would be prepared to consider special dispensation. But licences to re-export the fuel for reprocessing would be granted only in cases of "clear need". There could be no question of a general dispensation of the kind necessary to support the 10-year contracts under negotiation between the Japanese electricity industry and Britain and France.

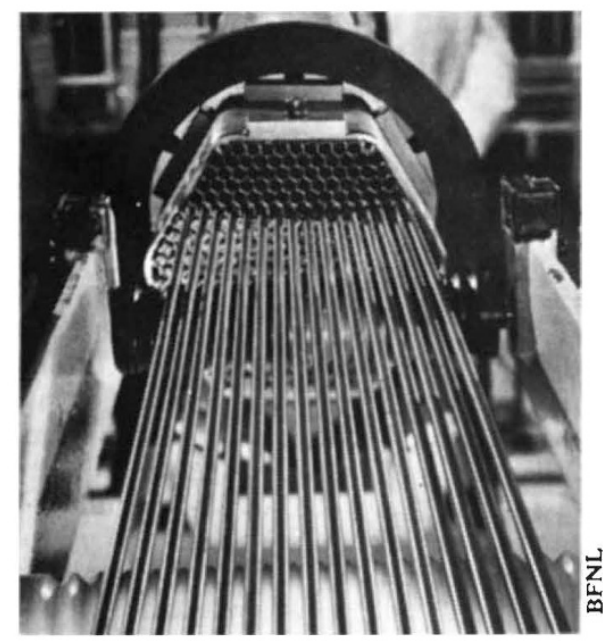

Plutonium fuel pins
These statements evoked widespread and sometimes vehement criticism from countries which would be immediately affected, notably those having no indigenous uranium but busy laying foundations for plutoniumfuelled fast breeder reactors to limit their dependence on uranium imports. One specific criticism levelled against the US was that for reasons of domestic expediency it was prepared to renounce one sensitive technology while expanding anather, enrichment; and using, moreover, a technology-the gas centrifuge-which only a few years before it had argued would pose a serious threat to the control of proliferation. More generally it was asked what guarantecs a nation could have for placing its faith in the US, whose own motives and intentions regarding fast reactors are uncertain.

Developing nations, whatever their nuclear aspirations, indignantly attacked what they saw as a rich nation's attempt to debar them from a valuable technology. The USSR, which has its own uranium reserves and also reprocesses spent fuel for its satellite nations, keeping the plutonium in Russia, has indicated that it will have nothing to do with President Carter's proposals. The policy could only hamper its own well-developed plans for fast reactors.

As with Russia, Britain has longstanding plans for safeguarding the future of its energy supplies once North Sea reserves run out by burning plutonium in fast reactors. Recycled in this way, Britain's existing stockpile of uranium has an energy content cxceeding that of proven coal reserves. Britain also has plans to use its knowledge of the difficult technology of reprocessing to develop an international service, under IAEA safeguards, for nations which would prefer not to embark on this technology, at least at this stage These plans could be severely hampered by US refusal to grant re-export licences for reprocessing to nations whose fuel has been enriched in the US.

Dr David Owen, the UK Foreign Secretary, in the fullest public response yet by any nation, on 10 May pointed out bluntly some of the weaknesses, as Britain sees it, of President Carter's anti-proliferation policy. He emphasised that Britain remained firmly committed to the principles of non-proliferation. But an effective antiproliferation policy "must go hand-inhand with a viable encrgy strategy", he said. He pointed to routes to nuclear explosives which the US policy would apparently leave uncontrolled. And he further implied that President Carter, far from improving relations, has seriously worsened them in this highly sensitive area of international affairs.

\section{Continued proliferation?}

A more realistic approach to the problem might be to assume that nuclear weapons will continue to proliferate. Although their attractions to terrorists have probably been greatly exaggerated, the attraction to governments remains undisputed. And governments would find it far easier to assemble the resources required to make credible nuclear explosives. In 1945 only one nation possessed these explosives. Through the McMahon Act the US debarred Britain, a partner in the Manhattan Project, from further participation in the technology. The UK Government, convinced that it needed the technology for broad reasons of national security, promptly embarked on its own nuclear programme. The USSR and France took similar decisions; and later China and India. An impressive 104 nations have signed the NPT, eschewing nuclear explosives; but another 30 have not, among them some with well-developed nuclear plans.

No moratorium on all, still less on parts, of the nuclear technologies by states already possessing nuclear weapons is credible as a way of stopping one of thuse 30 nations if it is determined, as Britain once was, to acquire the Bomb. It could even encourage it in such a quest. Neither need these nations try to buy large nuclear power stations costing around $\$ 1,000$ million as the source of plutonium. As a study specially commissioned by the US Congressional Research Service concluded last year, a small nation with ambitions for nuclear wcapons could satisfy them for an investment as small as $\$ 13$ million$\$ 26$ million, by building a small gascooled, graphite-moderated type of reactor, capable of making about 10 kilogrammes of plutonium a year. The design data for such a 'plutonium furnace' is already freely available in the open literature, and all the materials and components with the single exception of uranium-which is widely distributed across the Earth's surface-can be bought on the open market.

The UK Government estimates that about a dozen nations already have the basic knowledge and access to fissile materials. By 1987 another 20 could have reached this position. In short, it is already too late to prevent other nations from joining the nuclear club if they are determined to do so. A far more persuasive deterrent would be to create an international climate sufficiently hostile to nuclear proliferation to persuade any would-be aspirants that they would lose much more than they could possibly gain by possession of nuclear explosives. So far this has manifestly not been the case. 